\title{
AS INICIATIVAS DE REQUALIFICAÇÃO URBANA E SUAS INTENÇÕES NO BAIRRO CIDADE BAIXA EM PORTO ALEGRE (RS)
}

\section{Urban requalification initiatives and their intentions at cidade Baixa neigborhood in Porto Alegre (RS)}

\author{
Michelle Nascimento da Silva \\ Mestre em Planejamento Urbano e Regional - PROPUR/UFRGS \\ michelly ufrgs@hotmail.com
}

Artigo recebido em 09/09/2015 e aceito para publicação em 03/02/2016

DOI: $10.12957 /$ tamoios.2016.18511

Resumo Iniciativas de requalificação urbana nas áreas centrais das cidades vêm se mostrando como relevante universo de investigação. Há o interesse em compreender os rearranjos de significados urbanos e as consequências da permuta sociocultural que vêm legitimando o enobrecimento como estratégia de gestão dos lugares da cidade. Neste artigo, analisa-se o decreto 19.076 de 07/07/2015 que cria o Polo Gastronômico, Cultural e de Entretenimento com o objetivo de acelerar o ritmo de melhoramentos e da requalificação do bairro Cidade Baixa, em Porto Alegre (RS). São focalizadas especificamente as modificações ocorridas no bairro ao longo dos últimos 4 anos até o surgimento do decreto em 2015. A metodologia utilizada consiste na leitura crítica de matérias de diferentes meios de comunicação e legislação municipal, com a finalidade de observar as iniciativas de requalificação realizadas no bairro. Apesar de não totalmente perceptível, o bairro passou a ser cenário de um processo no qual a 'intensão gentrificadora' é utilizada como uma ferramenta que orienta sua reconfiguração.

Palavras-chave: gentrificação; bairro Cidade Baixa; requalificação urbana.

\begin{abstract}
Urban requalification initiatives in central areas of cities have been growing into a relevant universe of investigation. There is an interest in understanding the rearrangements of urban meanings and the consequences of sociocultural permutation that have been legitimizing the ennoblement as a management strategy of city places. This article analyses the decree 19.076 of 07/07/2015 which creates the Polo Gastronômico, Cultural e de Entretenimento (Entertainment, Cultural, and Gastronomic Center) that aims at accelerating the pace of improvements and the qualification of the Cidade Baixa neighborhood, in Porto Alegre (RS). The focus is specifically at the modifications made in the neighborhood in the last 4 years until the decree's arrival in 2015. The methodology used is based on the critical reading of articles from different means of communication and municipal legislations, in order to observe the initiatives of requalification in the neighborhood. In an initial transformation phase, Cidade Baixa presents some important developments. The neighborhood is now the scenery of a process in which the 'gentrification intension' is used as a tool guiding its reconfiguration, although it is not completely visible.
\end{abstract}

Keywords: gentrification; Cidade Baixa neighborhood; urban revitalization. 


\section{INTRODUÇ̃̃O}

Processos de requalificação urbana têm sido objeto de muitas pesquisas científicas (por exemplo, HAMNETT, 1996; SMITH, 2006; BIDOU-ZACHARIASEN, 2006; CRIEKINGEM, 2006), que buscam melhor compreender os mecanismos de reformulação dos espaços. Ao mesmo tempo, essas formas de intervenção mantêm-se vinculadas à gestão pública local que, por sua vez, investe frequentemente em modificações estratégicas de determinados lugares da cidade.

Tais formas de gestão da cidade estão intimamente ligadas ao fenômeno da gentrificação. A gentrificação consiste em um conjunto de processos simultâneos de transformação das áreas centrais urbanas em suas dimensões materiais, econômicas, sociais e culturais (BIDOU-ZACHARIASEN, 2006), e também no rearranjo da economia local, implicando o deslocamento de parte dos grupos de classes populares do centro (SMITH, 2006) e o enobrecimento dessas áreas através da inserção de um 'mix' de consumo e lazer redefinindo as características do lugar, bem como os seus usos (LEITE, 2004).

Nas décadas de 80 e 90, os projetos de revitalização das cidades, em escala global, foram objetos de estudos interessados em compreender o fenômeno da gentrificação e seus desdobramentos. Neste sentido, Bidou-Zachariasen (2006) afirma que a gentrificação pode ser reconhecida por meio de distintos estudos e abordagens em cidades que foram objeto de políticas de revitalização do centro. Em contextos diversos, verificam-se pontos convergentes nos modos de vida e nas políticas públicas urbanas.

Apesar disso, é importante sublinhar que a gentrificação não se apresenta da mesma forma em todos os locais, manifestando-se segundo o contexto específico de cada localidade (SMITH, 2006). Portanto, fazem-se indispensáveis estudos específicos com a finalidade de demonstrar sua pluralidade e viabilizar entendimentos com base em casos que estão associados a uma tendência global de reelaboração das cidades na atualidade. No caso do bairro Cidade Baixa, as formas de uso são voltadas ao entretenimento noturno. Nesse sentido, as iniciativas público-privadas buscam, nas palavras de Leite (2004, p. 25), "aliar consumo à tradição e patrimônio" o que transformaria o lugar em "enclaves para o consumo de uma nova classe média".

Este artigo estuda o recente projeto de requalificação do bairro Cidade Baixa, pertencente à região central de Porto Alegre/RS, mais especificamente a criação do Polo Gastronômico, Cultural e de Entretenimento Noturno, seus antecedentes desde 2011, as 
$\overline{\text { ações relativas à sua transformação e, também, seus desdobramentos sutis e pouco }}$ perceptíveis. O principal objetivo é analisar as iniciativas de intervenção voltadas para esse bairro a partir das intensões de formação de um contexto de gentrificação de consumo e frequêntação (BIDOU-ZACHARIASEN, 2006), ou seja, a que provoca uma modificação dos usos e do público não residente que frequenta o local. Utilizou-se a metodologia de análise de conteúdo para tratamento dos resultados.

\section{A REVITALIZAÇÃO dAS ÁREAS CENTRAIS E SEUS EFEITOS}

O processo de renovação dos bairros para revitalizar ou direcionar os usos espaciais para áreas específicas e escolhidas da cidade é uma tendência mundial nas metrópoles. A partir da década de 1970, assistem-se alguns fenômenos globais que mudaram a estrutura gerencial urbana tais como aqueles observados no bairro Cidade Baixa. Conforme Harvey (1996) os projetos específicos de um determinado lugar tornam-se foco de atenção pública e desvia o olhar dos problemas que afetam escalas globais, tornando o empreendedorismo crescente uma consequência desse processo. É o que o autor, denomina de um novo modo de gestão da cidade (HARVEY, 1996), um 'empresariamento' urbano cujas características passam pela busca por financiamentos com parcerias público-privadas, a execução de investimentos pontuais e especulativos, a visibilidade diante dos meios de comunicação e o estímulo à criação de espaços de entretenimento voltados para o setor turístico.

Essas estratégias em termos de gestão urbana, apesar de buscarem o progresso econômico das cidades são comumente acompanhadas do fenômeno da gentrificação. Segundo Bidou-Zachariasen (2006), o termo gentrificação foi originalmente utilizado por Ruth Glass (1963) para explicar o repovoamento de bairros desvalorizados de Londres nos anos 1960 por profissionais pertencentes à service class (GOLDTHORPE, 1995) implicando em uma mudança no perfil dos residentes. Mas essa noção foi sendo reapropriada e transformada conforme o curso da história. Sem perder a essência de modificação do perfil da população local, a gentrificação hoje é a recuperação através de iniciativas público e privadas dos centros degradados das cidades (SMITH, 2006). Isto é, a transformação funcional por meio de infraestrutura que acaba por provocar o encarecimento com a chegada de usuários com maior poder aquisitivo. Cabe salientar que a gentrificação não se detém apenas às transformações funcionais do local, mas também: simbólicas (por exemplo, o surgimento de novos discursos sobre os espaços); 
estruturais (por exemplo, o aparecimento de novas infraestruturas) e políticas, (por exemplo, o nascimento de novos marcos legislativos, novos grupos empresariais gestores, etc.). Por fim, é importante ressaltar que o encarecimento do custo de vida nas regiões decorre não somente da chegada de novos grupos sociais com poder aquisitivo distinto, mas também de investimentos do Estado em termos de regularização e renovação tributária.

Uma das definições mais completas e abrangentes para o conceito de gentrificação é a de Hamnett (1991). Para ele, trata-se de um fenômeno que é, ao mesmo tempo, físico, econômico, social e cultural. A gentrificação, usualmente, envolveria a inserção de grupos de maior poder aquisitivo em áreas que antes se mantinham ocupadas por grupos menos favorecidos economicamente. Em síntese, envolveria a renovação ou reabilitação física de uma área, até então degradada, e seu melhoramento para ir ao encontro das expectativas de consumo associadas ao estilo de vida dos novos grupos de usuários.

Com a tentativa de recuperação funcional das áreas administrativas e de negócio, no período de Pós-Guerra, a gentrificação ocorreu em muitas cidades europeias (por exemplo, Bruxelas, Lyon, Nápoles, Barcelona). Em seguida, houve a reprodução desse modelo para a América do Norte e a América Latina (por exemplo, Nova York, Cidade do México, São Paulo) sob uma perspectiva de inserção competitiva no mercado mundial por meio do capital imobiliário (BIDOU-ZACHARIASEN, 2006). Segundo Smith (2006), esse processo, guardadas as especificidades de cada cidade, integraria um modelo de planejamento urbano em escala global.

Num primeiro momento, os processos de enobrecimento sócioespacial se limitavam ao mercado residencial. No entanto, na medida em que novos grupos sociais foram se aproximando e se apropriando dos lugares, estes também foram transformados em lugares de lazer. As áreas centrais passaram a comportar grandes complexos culturais voltados não somente para o cidadão local, mas também para o turista (ARAÚJO, 2009). A partir do aumento das iniciativas de revitalização nas áreas centrais e, também, de pesquisas endereçadas a esse fenômeno, verifica-se a ampliação do conceito de gentrificação. Dessa forma, o sentido do termo deixa de ser exclusivamente residencial e passa a agregar as demandas comerciais e de movimentação de usuários.

Nessa perspectiva, Criekingen (2006), ao estudar a cidade de Bruxelas, observa a existência de dois tipos de gentrificação: uma predominantemente residencial, em fase incipiente, voltada para a produção de moradias para a classe média; e a gentrificação 
$\overline{\text { de consumo e frequentação, na qual a ocupação de imóveis vazios nas áreas centrais }}$ serve ao mercado do turismo e lazer através da construção de ambientes sofisticados. Ambas estimulam a produção glamurizada do espaço por meio da valorização do patrimônio histórico cultural, de produção de moradias e de investimentos na diversidade cultural, contando com o apoio e a divulgação da mídia, que auxilia na criação de um discurso dominante sobre o lugar para atrair consumidores cada vez mais selecionados. Nesta esteira, Criekingen (2006) propõe que o uso do termo gentrificação seja atribuído aos processos de produção de um espaço abastado e uniforme, tendo por base um espaço anteriormente degradado, independente de ser habitado ou não.

Siqueira (2014) sugere um modelo analítico para o estudo de processos de gentrificação voltado para a realidade brasileira, utilizando como caso ilustrativo de sua aplicabilidade as operações urbanas realizada na cidade de São Paulo. Tal modelo é alicerçado em três dimensões necessárias e definidoras do processo de gentrificação: 1) produção do espaço gentrificável; 2) elitização social com expulsão de grupos vulneráveis; e, 3) transformação da paisagem construída. A análise mostra que essas dimensões são mediadas por estruturas locais e, nestes casos, contextualizadas em projetos urbanísticos individuais.

Ao observar as estratégias de intervenção pública nas áreas centrais urbanas, é possível constatar que significativa parcela das decisões tomadas está ligada à valorização do patrimônio histórico material e imaterial. Entretanto, compartilhando das conclusões de Smith (2006), os referidos processos têm um objetivo que antecede a valorização do patrimônio. O escopo consiste em enobrecer determinados lugares da cidade mediante o reaproveitamento dos imóveis na modernização das atividades empresariais, na criação de empregos e, assim, na movimentação da economia local.

Ainda que essas intervenções aconteçam de distintas maneiras, segundo Melé (2006), é possível observar que elas compartilham das mesmas intenções, qual seja, diversificar as atividades, atrair investidores privados, fomentadores imobiliários e comerciais, bem como novas/os residentes. Já o fenômeno de gentrificação, para Sánchez (2001), faria parte da agenda social de renovação urbana. Nesse sentido, o que pode ser verificado é que os processos de valorização desses lugares e o encarecimento da moradia têm deslocado as populações de menor poder aquisitivo para fora das áreas centrais (SÁNCHEZ, 2001).

A Prefeitura Municipal de Porto Alegre (PMPA) foi uma das cidades que adotou novos padrões de planejamento e ações para adequar a administração pública aos 
padrões de gerenciamento empresariais, passando a utilizar o modelo de Planejamento Estratégico para gerir a cidade (PMPA, 2014). Os conceitos que orientam o processo estão baseados na configuração do Processo de Gestão da Estratégia Orientado a Resultados adaptados para as características das organizações públicas (PMPA, 2014). Um dos objetivos de seus programas estratégicos voltados para o eixo ambiência é efetuar a ampliação das vantagens competitivas locais. No caso da Cidade Baixa, a prefeitura formaliza a requalificação mediante o decreto número 19.076 de 07/07/2015. Essa legislação municipal busca acelerar o ritmo de desenvolvimento no bairro, com perspectivas de geração de emprego e renda. Para isso, oferece incentivo à atividade comercial e às atividades agregadas com a qualificação dos serviços oferecidos.

Ao adotar o planejamento estratégico para desenvolvimento das cidades, o poder público local lança o seu território em uma disputa econômica em escala global, fazendo com que parte de suas características se globalizem (SMITH, 2006). Nesse prisma, os projetos estratégicos nas áreas centrais urbanas buscam torná-las mais competitivas em relação às outras cidades, podendo comprometer certas características em determinada localidade em detrimento de outras com maior potencial competitivo.

\section{METODOLOGIA}

O estudo tem caráter exploratório-descritivo, realizado mediante pesquisa documental sobre as iniciativas voltadas para a melhoria do bairro. Teve-se como objetivo a compreensão do contexto de intervenções na Cidade Baixa. Para tanto, utilizou-se o levantamento documental (notícias em jornais e internet; e decretos municipais) como principal abordagem metodológica. Posteriormente, as fontes de evidência foram examinadas a partir da análise de conteúdo (BARDIN, 2011).

Quadro 1 - Síntese da metodologia

\begin{tabular}{|c|c|c|}
\hline \multicolumn{3}{|c|}{ Contexto de iniciativas de requalificação no bairro Cidade Baixa } \\
\hline $\begin{array}{c}\text { Técnicas de Coleta } \\
\text { de dados }\end{array}$ & Processo de coleta dos dados & $\begin{array}{c}\text { Abordagem de análise dos } \\
\text { dados }\end{array}$ \\
\hline Levantamento documental & $\begin{array}{l}\text { Seleção de notícias em jornais } \\
\text { Seleção de notícias na internet } \\
\text { Decreto } n^{\circ} 17.767 \text { de } 02 / 05 / 12 \\
\text { Decreto } n^{\circ} 17.902 \text { de } 07 / 08 / 12 \\
\text { Decreto } n^{\circ} 19.076 \text { de } 07 / 07 / 15 \\
\text { Dados estatísticos Secovi/RS }\end{array}$ & Análise de conteúdo \\
\hline
\end{tabular}

Fonte: Elaborado pela autora (2015) 
Inicialmente, realizou-se a pré-exploração do material a ser selecionado, com a intenção de apreender e organizar aspectos importantes para a próxima fase da análise. Posteriormente, houve a seleção das unidades de análise, a qual foi orientada pela temática de indícios de requalificação no bairro e seus desdobramentos no período de 2011 até 2015. Por fim, as fontes de evidências foram classificadas e agrupadas por semelhança.

\section{AS TRANSFORMAÇÕES DO BAIRRO CIDADE BAIXA}

A Cidade Baixa, na primeira metade do século $\mathrm{XX}$, mantinha uma relação contraditória com o restante da cidade. O bairro era portador de má fama, associada à marginalidade e ao crime, tendo por muito tempo sido evitado e estigmatizado. Simultaneamente, era conhecida por sua identidade boêmia com atividades específicas voltadas para a vida noturna, a música popular e o carnaval. Ao longo de sua história, a tradição boêmia na Cidade Baixa se acentuou ao ponto de persistir até a atualidade.

A partir da primeira metade do século XX, a população local aumentou sensivelmente em decorrência da supressão das poucas chácaras existentes e passaram a compor o bairro indústrias, cinemas e a sede paroquial (Igreja Sagrada Família). O bairro passou por diversas intervenções urbanísticas, pois contava com localização estratégica e privilegiada. Com a expansão urbana, a Cidade Baixa servia de meio de conexão com os demais lugares da cidade, especialmente a Zona Sul, pelo caminho da Azenha (FRANCO, 1998). Naquele período, foi elaborado o Plano de Melhoramentos com a finalidade de ligar o centro aos bairros. Na implantação do Estado Novo (19371945), fizeram-se as maiores obras viárias em Porto Alegre. Esses fatores conferiram centralidade ao bairro Cidade Baixa.

A intervenção urbanística mais expressiva ocorreu na segunda metade do século XX. Tratou- se da implantação do Projeto Renascença, executado pelo poder público municipal de Porto Alegre entre 1975 e 1979 com a finalidade de melhorar a infraestrutura urbana (SOUZA, 2008). Uma das ações mais impactantes do projeto foi a transposição da população favelada da região da Ilhota para o bairro Restinga para que essa fração do bairro Cidade Baixa fosse reurbanizada. Tais medidas promoveram a primeira onda de gentrificação no bairro e, também elevaram a atratividade do lugar.

Nos anos de 1980, a área oficial do bairro Cidade Baixa era contornada pelas perimetrais com corredores de ônibus que garantiam o deslocamento da população do 
centro para outros bairros (JARDIM, 1991). O bairro adquire novo formato e passa a acolher moradores de classe média. A partir dos anos de 1990, surgem movimentos espontâneos de revitalização cultural. A decadência do bairro Bom Fim, que foi espaço de lazer noturno de Porto Alegre, na década de 1980, atraiu investimentos para a Cidade Baixa (JARDIM, 1991).

Após algumas décadas, por volta de 1990, o bairro volta a ser cenário da vida noturna em Porto Alegre. O bairro aumenta sua visibilidade com a decadência da vida noturna existente no bairro Bom Fim, pois passa a receber também o público vindo de lá. O potencial histórico, bem como sua boa localização, fez do bairro área fértil para os empreendimentos voltados para o setor de gastronomia, lazer e entretenimento, especialmente o noturno. A reinauguração da vida noturna na Cidade Baixa se dá a partir da revitalização do bairro na década de 1990, atraindo diversos investimentos. A Cidade Baixa desde então vem sendo permeada por cíclicos processos de conflito entre moradores e comerciantes de bares e restaurantes noturnos -e, extensivamente, os seus frequentadores.

\section{DO CAOS AO POLO GASTRONÔMICO, CULTURAL E DE ENTRETENIMENTO}

O ápice dos problemas de convivência entre diferentes grupos de usuários no bairro ocorre em 2011. Entre os dias 10/11/2011 e 12/11/2011, ocorreu o fechamento de diversos estabelecimentos voltados ao entretenimento noturno, episódio que provocou muitos desdobramentos que perduram até os dias de hoje. De um lado, a vida noturna intensa, marcada por seus diversos estabelecimentos de entretenimento noturno, comerciantes e frequentadores; de outro lado, a vida residencial, marcada por seus moradores e suas contínuas reclamações sobre a falta de sossego. 


\title{
Figura 1 - Localização do Bairro Cidade Baixa em Porto Alegre/RS
}

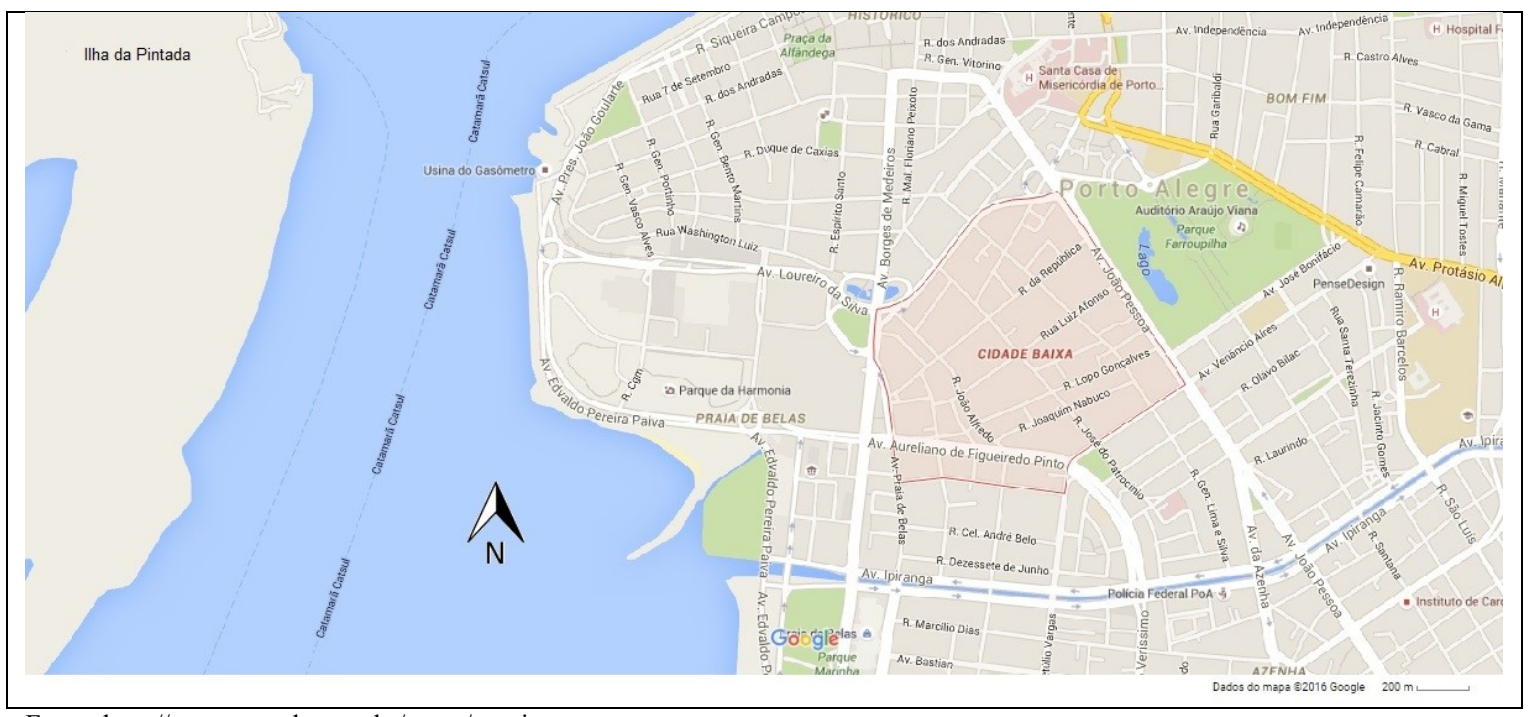

Fonte: http://www.google.com.br/maps/preview.

Diante de diversas formas de repercussão da medida de fechamento dos estabelecimentos noturnos, o poder público municipal assinala o que seria o primeiro indício de mudanças no bairro. Pode-se depreender melhor a questão através de trecho da manchete Polêmica na Cidade Baixa servirá para aperfeiçoamentos, defende

\section{Nagelstein:}

\begin{abstract}
"A crise sempre serve para aperfeiçoamento", afirmou o titular da Secretaria Municipal da Produção, Indústria e Comércio (Smic), Valter Nagelstein, ao admitir que a legislação pode ser revista para que bares possam funcionar depois da meia-noite em Porto Alegre. Ele apontou que a polêmica operação realizada há cerca de dez dias, que fechou 22 bares no bairro mais boêmio da Capital, deve fazer com que o poder público reveja leis confusas que prejudicam a atividade comercial noturna, mas também para que empresários e cidadãos tenham mais responsabilidade com a cidade. (PRESTES, 2011).
\end{abstract}

Em dezembro de 2011, é criado oficialmente o Grupo de Trabalho (GT) Cidade Baixa para buscar soluções aos problemas do bairro. Tal iniciativa teve por objetivo permitir que moradores e comerciantes, conjuntamente com o poder público, pudessem debater e encaminhar soluções aos assuntos que estavam gerando conflitos de usos. A partir disso, o referido GT realizou diversas reuniões na busca de soluções para as questões do bairro.

Seria em 2012 que o bairro Cidade Baixa voltaria a receber sinais de reformulação. A primeira medida de aperfeiçoamento proposta para o bairro foi através do Decreto Municipal no 17.767 de 02/05/2012, que estabeleceu três níveis de polarização onde os estabelecimentos voltados ao entretenimento noturno podem funcionar. 
$\S 3^{\circ}$ Para o Bairro Cidade Baixa, ficam definidos os seguintes níveis de polarização: I - nível de polarização 1: Rua João Alfredo, entre a Rua da República e Av. Aureliano de Figueiredo Pinto; II - nível de polarização 2: Rua da República, entre a Rua João Alfredo e Av. João Pessoa, e Rua General Lima e Silva, entre a Rua Venâncio Aires e Av. Loureiro da Silva; III - nível de polarização 3: demais vias do Bairro Cidade Baixa. (PMPA, 2012).

O primeiro nível de polarização comportaria elevada concentração de bares e restaurantes com funcionamento noturno. O segundo permitiria um grau de concentração menos intenso que a primeira. Já o terceiro ofereceria uma concentração mais branda de atividades noturnas.

A segunda medida adotada foi a de reestabelecer o horário de funcionamento das atividades de bares, restaurantes, cafés e lancherias no Bairro Cidade Baixa mediante o Decreto Municipal de Porto Alegre no 17.902 de 07/08/2012:

I - sextas-feiras, sábados e vésperas de feriados até às $2 \mathrm{~h} 00 \mathrm{~min}$, com tolerância de 30 (trinta) minutos, conforme determina o inc. IV do art. $1^{\circ}$ da Lei Complementar $\mathrm{n}^{\circ} 415$, de 7 de abril de 1998, incluído pela Lei Complementar $\mathrm{n}^{\circ} 623$, de 23 de junho de 2009; e II - de domingo à quintafeira até a $01 \mathrm{~h} 00 \mathrm{~min}$, com tolerância de 30 (trinta) minutos, sendo que após as 00h00min, observado o disposto no inciso IV do art. $1^{\circ}$ da Lei Complementar $n^{\circ} 415$, de 1998, incluído pela Lei Complementar $n^{\circ} 623$, de 2009, não serão permitidas mesas em recuos e em passeios públicos fronteiros aos estabelecimentos, bem como o funcionamento de "decks" externos e áreas abertas. (PMPA, 2012).

Junto a essas iniciativas em busca de melhorias para o bairro, foi criada pela associação dos comerciantes do bairro o projeto de requalificação do bairro denominado "Cidade Baixa em Alta". Esse projeto foi criado com o objetivo de resgatar as atividades culturais e de entretenimento no bairro e, assim, promover a revalorização do mesmo. Neste sentido, iniciativas foram desenvolvidas, por exemplo através de diversas atividades culturais. Dentre elas foram realizados piqueniques no Museu Joaquim Felizardo, carnavais de rua, festas juninas, rodas de samba, intervenções artísticas com grafite e dança, festivais de rock, shows, etc.

$\mathrm{O}$ argumento inicial dessas iniciativas no bairro Cidade Baixa se alicerçou em uma política de valorização de espaços para as atividades culturais na rua e para a manutenção das condições de vida dos moradores e comerciantes locais. Isso pode ser melhor observado na manchete Parceria fortalece ações na Cidade Baixa: 
Cidade Baixa em Alta - A associação dos comerciantes iniciou há três meses o projeto "Cidade Baixa em Alta", movimento que pretende envolver frequentadores, moradores e empresários em ações de conscientização e valorização do bairro. Como explicou Tiago Fáccio, um dos responsáveis criativos da iniciativa, o objetivo é envolver as partes e exaltar o que a Cidade Baixa tem de positivo. "Queremos que todo mundo se sinta parte do bairro. Com ações educativas, buscamos a conscientização", definiu.

Além de recorrer às plataformas virtuais de comunicação, como as redes sociais, o movimento realiza ações presenciais no bairro para atingir os públicos online e off-line. A programação já incluiu ações como exibições de artistas de rua, cinema ao ar livre e piquenique cultural, e pretende avançar em ações de fidelização. Para Fortunati, o projeto é inovador e tem potencial transformador, porque integra as pessoas. "A prefeitura quer continuar sendo parceira dos empreendedores, que fomentam a economia e a geração de emprego e renda", afirmou o prefeito. (SEEGER, 2012).

Como estratégia de fomento das atividades locais de comércio, foram oferecidas pela prefeitura linhas de crédito, consultorias e capacitação em gestão empresarial através de parcerias entre a Secretaria Municipal da Produção, Indústria e Comércio Smic - e o Serviço de Apoio às Micro e Pequenas Empresas - Sebrae/RS, bem como a possibilidade de formalizar pequenos negócios (TEIXEIRA, 2012). Gradativamente, as iniciativas direcionadas ao bairro vão adquirindo um caráter comercial que busca na regulamentação das atividades noturnas do bairro a maneira de selecionar o tipo de comerciante que poderá permanecer em atividade no local. Nas palavras do presidente do SINDPOA (Sindicato da Hotelaria e Gastronomia de Porto Alegre), José de Jesus Santos: "Vamos poder separar o joio do trigo, ou seja, o empresário que não está de acordo com a lei daquele que está completamente regularizado. Porque o irregular prejudica o setor, prejudica quem presta um bom serviço aos frequentadores sem causar problemas no bairro" (PMPA, 2012).

A partir disso, sucessivas ações para selecionar e forçar a regularização das atividades noturnas foram realizadas, como pode ser observado pelas notícias divulgadas no site da Prefeitura Municipal de Porto Alegre (PMPA):

Quadro 2 - Título das notícias sobre regularização das atividades noturnas

\begin{tabular}{|c|l|c|}
\hline Fonte & \multicolumn{1}{|c|}{ Título } & Mês/Ano \\
\hline PMPA & Ação na Cidade Baixa deve regularizar cerca de 100 bares & $10 / 2012$ \\
\hline PMPA & Smic realiza ação para regularizar bares na Cidade Baixa & $10 / 2012$ \\
\hline PMPA & Realizada mais uma ação integrada no bairro Cidade Baixa & $10 / 2012$ \\
\hline PMPA & Cidade Baixa: Smic realiza terceira ação para regularizar bares & $10 / 2012$ \\
\hline PMPA & Prazo para regularização de bares da Cidade Baixa vai até sexta & $11 / 2012$ \\
\hline PMPA & Hoje é o último dia para regularização de bares na Cidade Baixa & $11 / 2012$ \\
\hline PMPA & Smic recadastra 154 bares na Cidade Baixa & $11 / 2012$ \\
\hline
\end{tabular}


A partir de 2013 (Quadro 3), inicia o surgimento de movimentos em direção à requalificação do bairro com a entrega de uma ciclovia, a elaboração de nova rota de transporte público, a promoção de eventos turísticos e a qualificação dos serviços. Ainda nesse período, dá-se o começo de seus desdobramentos no sentido de formalizála com a criação do polo gastronômico por meio de seminários e reuniões:

Quadro 3 - Título das notícias sobre requalificação

\begin{tabular}{|l|l|c|}
\hline Fonte & \multicolumn{1}{|c|}{ Título } & Mês/Ano \\
\hline PMPA & Prefeitura entrega ciclovia da Cidade Baixa à população & $06 / 2013$ \\
\hline PMPA & Linha Circular Urca terá desvio na Cidade Baixa & $12 / 2013$ \\
\hline PMPA & Cidade Baixa no roteiro da Caminhada Turística de Verão & $02 / 2014$ \\
\hline PMPA & Prefeitura leva microcrédito à Cidade Baixa & $03 / 2014$ \\
\hline PMPA & Cidade Baixa terá ação para qualificar limpeza & $04 / 2014$ \\
\hline PMPA & Bares da Cidade Baixa ganham certificação de descarte de resíduos & $05 / 2014$ \\
\hline PMPA & DEP conclui drenagem na Praça Laurentino Zottis, na Cidade Baixa & $05 / 2014$ \\
\hline PMPA & Seminário discute criação de polo na Cidade Baixa & $09 / 2014$ \\
\hline PMPA & Secretaria de Obras revitaliza ruas da Cidade Baixa & $02 / 2015$ \\
\hline PMPA & Reunião discute Polo Gastronômico na Cidade Baixa & $03 / 2015$ \\
\hline PMPA & Moradores da Cidade Baixa e prefeitura planejam ações no bairro & $04 / 2015$ \\
\hline PMPA & Polo Gastronômico é criado para qualificar a Cidade Baixa & $07 / 2015$ \\
\hline
\end{tabular}

Fonte: Elaborado pela autora (2015).

O processo de valorização do bairro Cidade Baixa vem sendo associado também ao surgimento de novos empreendimentos imobiliários multifuncionais que reúnem, em um mesmo projeto, unidades residenciais, comerciais, serviços, centros de compras e conveniência, o que se denomina como conceito mixed-use (SCHWANKE, 2003). Os anúncios normalmente buscam salientar a vocação gastronômica, cultural e de entretenimento do bairro com a finalizade de atrair compradores. Isso pode ser observado no empreendimento "Spot Cidade Baixa" (Figura 2) da incorporadora e construtora Melnick Even; "um lugar para deixar sua vida ainda mais fácil. O bairro Cidade Baixa se caracteriza, entre outras coisas, pela grande quantidade de bares e restaurantes, local preferido de jovens e intelectuais" (MELNICK EVEN, 2012). 


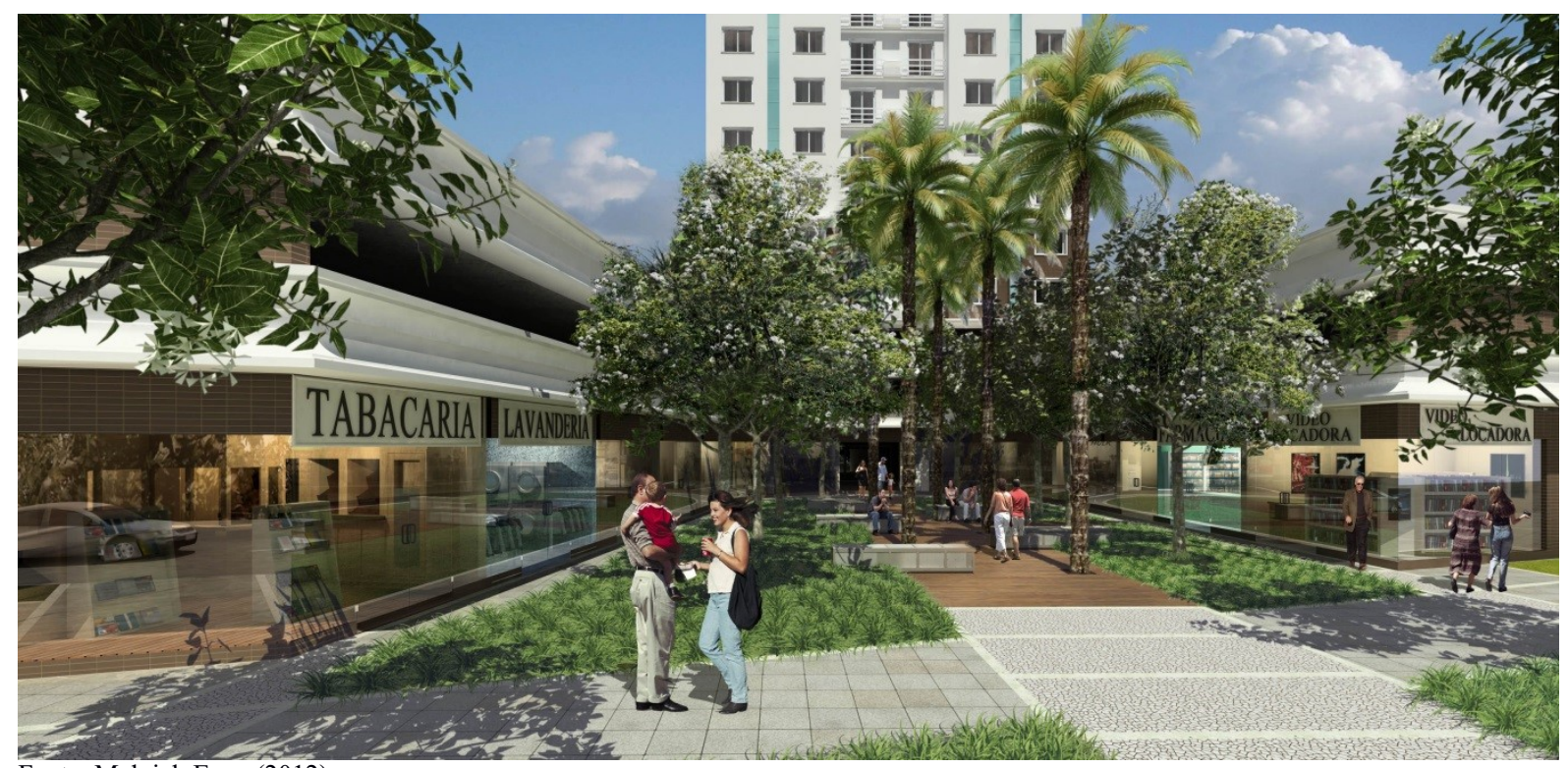

Fonte: Melnick Even (2012).

Em 2015, é possível verificar, também sob o conceito mixed-use, o lançamento do empreendimento "Artsy" (Figura 3) da incorporadora e construtora Maiojama; "bares, atividade cultural e comportamento. Cafés, livrarias, parques, shows e atitude. Lojas, supermercado, restaurantes e convicções. Mais do que um bairro, a Cidade Baixa é um estilo de vida. Com liberdade de pensar e liberdade de se movimentar. Aqui todos chegam, tudo é dito e ouvido. É o lugar onde tudo acontece, tudo está perto e todos participam. Onde não basta parecer. É preciso significar (MAIOJAMA, 2015).

Figura 03: Lançamento do empreendimento Artsy - Maiojama

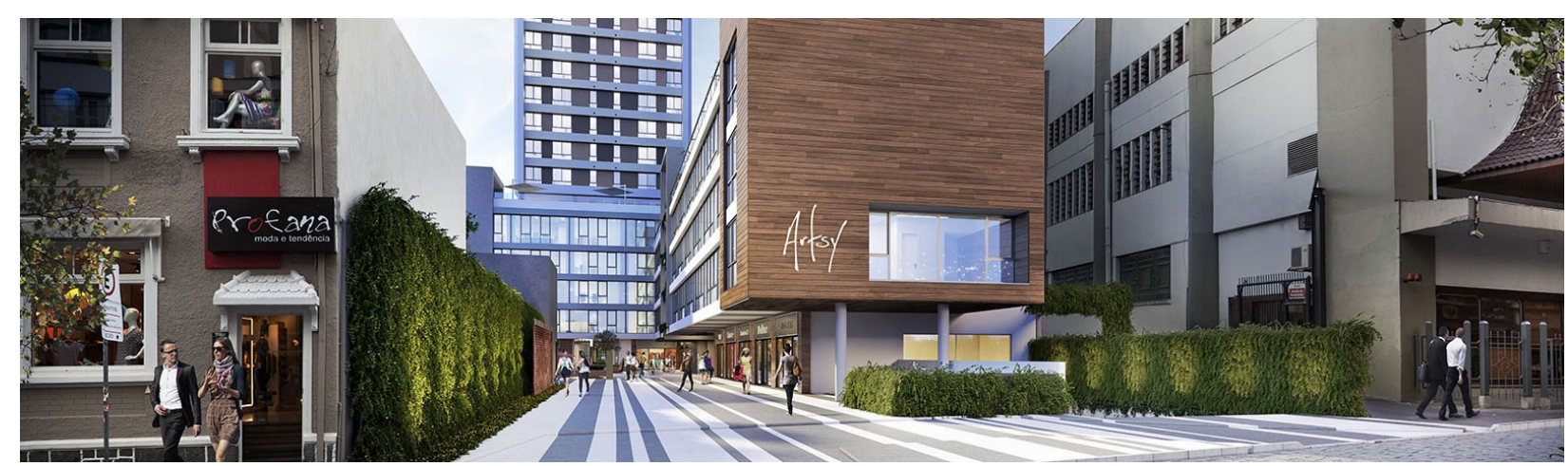

Fonte: Maiojama (2015).

O diretor-executivo da Maiojama, Antônio Pedro Rodriguez Teixeira, em entrevista sobre o empreendimento Artsy, revela a percepção sobre as oportunidades do bairro: "Quem vive a corporação imobiliária está sempre garimpando oportunidades. E 
como estamos sempre atrás de um nicho, entendemos que a Cidade Baixa poderia ser toda a tônica do projeto" (PANDOLFI, 2015).

Com a criação do Decreto Municipal no 19.076 de 07/07/2015 que cria o Polo Gastronômico, Cultural e de Entretenimento no Bairro Cidade Baixa (PMPA, 2015), pode-se observar em algumas notícias referentes a ele a existência de elementos de tônica gentrificadora:

\begin{abstract}
Substituição de público: entre os principais objetivos de oficializar a Cidade Baixa como polo, o que talvez mais alie empresários e moradores, é a busca, com a revitalização de casas e passeios, de um público diferente ao que, hoje, afirmam causar problemas: aqueles que, em vez de frequentar os bares, prefere consumir nas ruas. (...) Apesar disso, seria preocupação do polo, também, dar uma opção a este público que, embora não desejado, encontra hoje, na Cidade Baixa, sua referência. (DAROIT, 2015).
\end{abstract}

Parcerias público-privadas: Conforme o documento (Decreto ${ }^{\circ} 19.076$ ), os estabelecimentos integrantes do polo, com o poder público e os demais órgãos da iniciativa privada, promoverão ações coordenadas para melhorar os investimentos na Cidade Baixa. As entidades representativas dos grupos empresariais também poderão propor e custear com recursos privados, obras ou ações de melhoria para o bairro, desde que aprovadas pelo Comitê de Trabalho e devidamente licenciadas pelos órgãos competentes. (...) A presidente da Associação dos Amigos da Cidade Baixa, Roberta Rosito Corrêa, julga ser "muito importante" a formação do polo. "Isso vai trazer investimentos privados, através de financiamento de empresas como Caixa, Santander, para participar do projeto de revitalização do bairro. Vai suprir necessidades financeiras que a Prefeitura não tem como investir no momento", afirma. (FOGLIATTO, 2015).

A qualificação das atividades comerciais locais através da parceria com o SEBRAE/RS, bem como o fomento ao crescimento econômico e geração de empregos, vem se fazendo perceptíveis no que se refere à modificação da apropriação e consumo do lugar. Neste sentido, o preço do $\mathrm{m}^{2}$ vem sofrendo mudanças gradativas a partir da implementação do conjunto de iniciativas adotadas pelos empresários em busca de melhorias para o bairro. De acordo com o SECOVI/RS (2015), em 2012, a média do valor do metro quadrado dos imóveis atingia o montante aproximado de $\mathrm{R} \$$ $3.073,36 / \mathrm{m}^{2}$, variando em torno de $\mathrm{R} \$ 240,25$ a mais no ano seguinte. Em 2014, no mesmo bairro, o preço passaria a uma média de $\mathrm{R} \$ 3.820,58 / \mathrm{m}^{2}$, atingindo no período de janeiro a julho de 2015 o valor de aproximadamente $\mathrm{R} \$ 3.966,71$ para compra.

Os empreendimentos imobiliários buscaram oferecer um padrão construtivo direcionado a moradores jovens, ajustando-o a seu estilo de vida e consumo. A valorização do patrimônio cultural e o regramento da vida noturna na Cidade Baixa também contribuíram para que esse bairro voltasse a ser apropriado por diversos grupos 
de usuários, distanciando-se, assim, do período de caos vivenciado em 2011, nas palavras do Prefeito José Fortunati:

\begin{abstract}
Não podemos perder a visão de que a Cidade Baixa é um bairro boêmio e cultural extremamente fortalecido, mas que, como qualquer zona da cidade, precisa ser regrado. O desregramento estava gerando confusões, incompreensões e discussões. Estávamos vivendo uma guerra civil na Cidade Baixa.(...) Criamos um novo conceito, tanto que agora há o movimento Cidade Baixa em Alta, que é para valorizar o bairro, e nós somos parceiros (OLIVEIRA, 2012).
\end{abstract}

A partir das três dimensões analíticas de Siqueira (2014), a intensão gentrificadora das diversas iniciativas de qualificação do bairro pode ser percebida ante a:

Produção do espaço gentrificável: a identificação do bairro como um lugar que demanda investimentos da iniciativa público e privada, face ao período de degradação vivenciado em 2011. Por exemplo, "Estávamos vivendo uma guerra civil na Cidade Baixa" (...) Criamos um novo conceito, tanto que agora há o movimento Cidade Baixa em Alta, que é para valorizar o bairro, e nós somos parceiros" (OLIVEIRA, 2012); "Parecia que tinha acabado a Cidade Baixa. Vimos que era preciso montar uma solução, conversar com o poder público e moradores, ou todos iriam fechar" (DAROIT, 2015).

Elitização social com expulsão de grupos vulneráveis: seleção de usos e usuários que serão alvo de estímulo e o fomento aos mercados imobiliário e de entretenimento noturno locais. Por exemplo, "entre os principais objetivos de oficializar a Cidade Baixa como polo, o que talvez mais alie empresários e moradores é a busca, com a revitalização de casas e passeios, de um público diferente” (...) "dar uma opção a este público que, embora não desejado, encontra hoje, na Cidade Baixa, sua referência" (DAROIT, 2015).

Transformação da paisagem construída: as parcerias público-privadas reconhecidas mediante o Decreto $\mathrm{n}^{\circ} 19.076$ de 07/07/2015, permitindo às empresas proporem e custearem obras ou ações de requalificação do bairro. Por Exemplo, “Art. $8^{\mathrm{o}}$ - Os estabelecimentos integrantes do polo em conjunto com a municipalidade e os demais órgãos da iniciativa privada, promoverão ações coordenadas para melhorar os investimentos privados e públicos no bairro Cidade Baixa, observando as características locais e respeitando a legislação vigente" (PMPA, 2015). 


\section{À GUISA DE CONCLUSÃO}

Considerando que o projeto de requalificação para o bairro Cidade Baixa está em fase inicial, isto é, o bairro encontra-se atualmente dentro do período de diagnóstico, não é possível projetar com precisão as proporções que terão as transformações geradas a partir das propostas de intervenção originadas pela avaliação do projeto de implantação do Polo. Conquanto, é possível depreender que a maneira como se deram os encaminhamentos para a melhoria do bairro ao longo dos últimos anos tende a criar um cenário favorável para o mercado imobiliário e os estabelecimentos comerciais. É possível afirmar a partir das evidências analisadas que a 'intensão gentrificadora' está direcionada para a gentrificação de consumo e frequentação (CRIEKINGEN, 2006). Esse processo parece instigar a substituição gradativa de grupos de frequentadores que, pelo estilo de vida e consumo que apresentam, poderão não ser alcançados pelos usos oferecidos. Paralelo a isso, face ao potencial de valorização local, o mercado imobiliário vem enxergando oportunidades de investimento na área. Entretanto, nas evidências estudadas não se constata a existência de uma 'intenção gentrificadora' do tipo residencial, destacando-se o interesse dos agentes imobiliários em investimentos do tipo comercial.

O bairro Cidade Baixa se apresenta em consonância com alguns aspectos encontrados em outras cidades europeias e latino-americanas no que diz respeito ao processo de requalificação. Ou seja, tais processos priorizam uma transformação mais pautada pela ocupação de frequentadores para o lazer e consumo e não tanto residencial, como pensada na literatura clássica que aborda o tema.

\section{REFERÊNCIAS}

ARAÚJO, Vanessa Jorge de. Lapa carioca: uma (re)apropriação do lugar. Dissertação de mestrado. Universidade Federal do Rio de Janeiro. Instituto de Pesquisa e Planejamento Urbano e Regional. Programa de Pós-Graduação em Planejamento Urbano e Regional, 2009.

BARDIN, L. Análise de Conteúdo. Lisboa, Portugal; Edições 70, LDA, 2011.

BARROSO, L. Prefeitura entrega ciclovia da Cidade Baixa à população. Prefeitura Municipal de Porto Alegre, Porto Alegre, jun. 2013. Disponível em $<$ http://www2.portoalegre.rs.gov.br/> Acesso em: 15 ago. 2015.

BERTUZZI, B.; CARNEIRO, C. (2015). Bares da Cidade Baixa ganham certificação de descarte de resíduos. Prefeitura Municipal de Porto Alegre, Porto Alegre, mai. 2014. Disponível em <http://www2.portoalegre.rs.gov.br/> Acesso em: 15 ago. 2015. 
BERTUZZI, B. (2015). Reunião discute Polo Gastronômico na Cidade Baixa. Prefeitura Municipal de Porto Alegre, Porto Alegre, março. Disponível em $<$ http://www2.portoalegre.rs.gov.br/> Acesso em: 15 ago. 2015.

BIDOU-ZACHARIASEN, C. et al. De volta à cidade: dos processos de gentrificação às políticas de "revitalização" dos centros urbanos. São Paulo: Annablume, 2006.

CRIEKINGEN, Mathieu van. A cidade renasce! Formas, políticas e impactos da revitalização residencial em Bruxelas. In: BIDOU-ZACHARIASEN, C. et al. De volta à cidade: dos processos de gentrificação às políticas de "revitalização" dos centros urbanos. São Paulo: Annablume, 2006.

DAROIT , G. Cidade Baixa quer virar polo oficial de lazer. Tradicional reduto boêmio da Capital, bairro se estrutura para mudar de status. Jornal do Comércio, Porto Alegre, mai. 2015. Disponível em <http://jcrs.uol.com.br/> Acesso em: 15 ago. 2015.

FERNANDES, M. Ação na Cidade Baixa deve regularizar cerca de 100 bares. Prefeitura Municipal de Porto Alegre, Porto Alegre, out. 2012. Disponível em $<$ http://www2.portoalegre.rs.gov.br/> Acesso em: 15 ago. 2015.

. Smic realiza ação para regularizar bares na Cidade Baixa. Prefeitura Municipal de Porto Alegre, Porto Alegre, out. 2012. Disponível em $<$ http://www2.portoalegre.rs.gov.br/> Acesso em: 15 ago. 2015.

- Realizada mais uma ação integrada no bairro Cidade Baixa. Prefeitura Municipal de Porto Alegre, Porto Alegre, out. 2012. Disponível em $<$ http://www1.prefpoa.com.br/> Acesso em: 15 ago. 2015.

. Cidade Baixa: Smic realiza terceira ação para regularizar bares. Prefeitura Municipal de Porto Alegre, Porto Alegre, out. 2012. Disponível em $<$ http://www2.portoalegre.rs.gov.br/> Acesso em: 15 ago. 2015.

. Prazo para regularização de bares da Cidade Baixa vai até sexta. Prefeitura Municipal de Porto Alegre, Porto Alegre, nov. 2012. Disponível em $<$ http://www2.portoalegre.rs.gov.br/> Acesso em: 15 ago. 2015.

. Hoje é o último dia para regularização de bares na Cidade Baixa. Prefeitura Municipal de Porto Alegre, Porto Alegre, nov. 2012. Disponível em $<$ http://www2.portoalegre.rs.gov.br/> Acesso em: 15 ago. 2015.

Smic recadastra 154 bares na Site PMPA Cidade Baixa. Prefeitura Municipal de Porto Alegre, Porto Alegre, nov. 2012. Disponível em $<$ http://www2.portoalegre.rs.gov.br/> Acesso em: 15 ago. 2015.

Seminário discute criação de polo na Cidade Baixa. Prefeitura Municipal de Porto Alegre, Porto Alegre, set. 2014. Disponível em $<\mathrm{http}$ ///www2.portoalegre.rs.gov.br/> Acesso em: 15 ago. 2015.

FOGLIATTO, D. Com criação de polo gastronômico, comerciantes esperam mais investimentos na Cidade Baixa. Sul21, Porto Alegre, jul. 2015. Disponível em $<$ http://www.sul21.com.br/> Acesso em: 15 ago. 2015.

FRANCO, Sérgio da Costa. Porto Alegre: Guia Histórico. $3^{\mathrm{a}}$ ed. Porto Alegre: EdUFRGS, 1998. 
HAMNETT, C. Les aveugles et l'éléphant: l'explication de la gentrification. In: Strates 9, $1996-97$.

HARVEY, David. Condição Pós-Moderna: uma pesquisa sobre as origens da mudança cultural. $6^{\text {a }}$ ed. São Paulo: Loyola, 1996.

Do gerenciamento ao empresariamento: a transformação da administração urbana no capitalismo tardio. São Paulo, Espaço e Debates, nº 39, 1996, p. 48-64.

JARDIM, Denise Fagundes. De bar em bar: identidade masculina e auto-segregação entre homens de classes populares. Dissertação de mestrado. Universidade Federal do Rio Grande do Sul. Instituto de Filosofia e Ciências Humanas. Programa de PósGraduação em Antropologia Social, 1991.

JUNIOR, R R. Cidade Baixa terá ação para qualificar limpeza. Prefeitura Municipal de Porto Alegre, Porto Alegre, abr. 2014. Disponível em $<$ http://www2.portoalegre.rs.gov.br/> Acesso em: 15 ago. 2015.

LEAL, F. Linha Circular Urca terá desvio na Cidade Baixa. Prefeitura Municipal de Porto Alegre, Porto Alegre, dez. 2013. Disponível em $<$ http://www2.portoalegre.rs.gov.br/> Acesso em: 15 ago. 2015.

LEITE, Rogério Proença. Contra-usos da Cidade: lugares e espaço público na experiência contemporânea. Campinas: Ed Unicamp: Aracajú, Ed UFS, 2004.

MAIOJAMA, Construtora e Incorporadora. Projeto Artsy. Porto Alegre, 2015. Disponível em $<\mathrm{http}$ :/www.maiojama.com.br $>$ Acesso em: 10 ago. 2015.

MELÉ, P. (Re) investir nos espaços centrais das cidades mexicanas. In: BIDOUZACHARIASEN, C. et al. De volta à cidade: dos processos de gentrificação às políticas de revitalização dos centros urbanos. São Paulo, Annablume, 2006.

MELNICK, Construtora e Incorporadora. Projeto Spot Cidade Baixa. Porto Alegre, 2012. Disponível em <http://www.melnick.com.br > Acesso em: 10 ago. 2015.

OLIVEIRA, M. Parceria entre a Prefeitura e empresários quer revitalizar Cidade Baixa. Melhorias nas calçadas e fachadas estão previstas. Zero Hora, Porto Alegre, jul. 2015. Disponível em <http://zh.clicrbs.com.br/> Acesso em: 15 ago. 2015.

OLIVEIRA, S. Fortunati: "Estávamos vivendo uma guerra civil na Cidade Baixa". Sul21, Porto Alegre, ago. 2012. Disponível em < http://www.sul21.com.br/ $>$ Acesso em: 15 ago. 2015.

PANDOLFI, F. Artsy: Porto Alegre está prestes a ganhar mais um estabelecimento de convivência. Rede Social. Zero Hora, Porto Alegre, mar. 2015. Disponível em $<$ http://wp.clicrbs.com.br/> Acesso em: 15 ago. 2015.

PEREIRA, O. Moradores da Cidade Baixa e prefeitura planejam ações no bairro. Prefeitura Municipal de Porto Alegre, Porto Alegre, abr. 2015. Disponível em $<\mathrm{http}$ ://www2.portoalegre.rs. gov.br/> Acesso em: 15 ago. 2015.

PREFEITURA MUNICIPAL DE PORTO ALEGRE. Modelo de gestão 2014-2015. Porto Alegre, 2014.

PREFEITURA MUNICIPAL DE PORTO ALEGRE. Decreto $\mathbf{n}^{\circ}$ 17.767, 02 de maio de 2012. Acrescenta $\S 3^{\circ}$ ao art. $2^{\circ}, \S \S 3^{\circ}, 4^{\circ}$ e $5^{\circ}$ no art. $3^{\circ}$ e o $\S 2^{\circ}$ no art. $6^{\circ}$ do Decreto $\mathrm{n}^{\mathrm{o}} 14.607$, de 28 de julho de 2004 . 
PREFEITURA MUNICIPAL DE PORTO ALEGRE. Decreto $\mathbf{n}^{\circ} \mathbf{1 7 . 9 0 2 ,} 07$ de agosto de 2012. Estabelece o horário de funcionamento das atividades de bar, restaurante, café e lancheria no Bairro Cidade Baixa.

PREFEITURA MUNICIPAL DE PORTO ALEGRE. Decreto n* 19.076, de julho de 2015. Cria o Polo Gastronômico, Cultural e de Entretenimento da Cidade Baixa, compreendendo o polígono formado pela Av. João Pessoa, Av. Loureiro da Silva, Av. Praia de Belas, Rua Barão do Gravataí, Av. Getúlio Vargas, Praça Garibaldi, Av. Venâncio Aires.

PRESTES, F. Polêmica na Cidade Baixa servirá para aperfeiçoamentos, defende Nagelstein. Sul21, Porto Alegre, nov. 2011. Disponível em < http://www.sul21.com.br/> Acesso em: 15 ago. 2015.

SÁNCHEZ, Fernanda. A reinvenção das cidades na virada do século: agentes, estratégias e escalas de ação política. Revista Sociologia Política, Curitiba, nº 16, p.3149, jun. 2001.

SANTANA, L.; MACHADO, A. DEP conclui drenagem na Praça Laurentino Zottis, na Cidade Baixa. Prefeitura Municipal de Porto Alegre, Porto Alegre, mai. 2014. Disponível em <http://www2.portoalegre.rs.gov.br/> Acesso em: 15 ago. 2015.

SCHIFINO, A. Prefeitura leva microcrédito à Cidade Baixa. Prefeitura Municipal de Porto Alegre, Porto Alegre, mar. 2014. Disponível em $<$ http://www2.portoalegre.rs.gov.br/> Acesso em: 15 ago. 2015.

SCHWANKE, D.; PHILLIPS, P. L; SPINK, F. Mixed-Use Development - Handbook, second edition. ULI (Urban Land Institute), Washington DC, 2003.

SEEGER, C. Parceria fortalece ações na Cidade Baixa. Prefeitura Municipal de Porto Alegre, Porto Alegre, jun. 2012. Disponível em <http://www2.portoalegre.rs.gov.br/> Acesso em 15 ago. 2015.

SERRA, C. Cidade Baixa no roteiro da Caminhada Turística de Verão. Prefeitura Municipal de Porto Alegre, Porto Alegre, fev. 2014. Disponível em $<$ http://www2.portoalegre.rs.gov.br/> Acesso em: 15 ago. 2015.

SIQUEIRA, Marina Toneli. Entre o fundamental e o contingente: dimensões da gentrificação contemporânea nas operações urbanas em São Paulo. Caderno Metrópoles, São Paulo, v. 16, n. 32, pp. 391-415, nov. 2014.

SOUZA, Anita Silva de. Projeto Renascença: um caso de gentrificação em Porto Alegre durante a década de 1970. Dissertação de Mestrado, UFRGS, 2008.

TAVARES, P.; TURELA, L. Secretaria de Obras revitaliza ruas da Cidade Baixa. Prefeitura Municipal de Porto Alegre, Porto Alegre, fev. 2015. Disponível em $<$ http://www2.portoalegre.rs.gov.br/> Acesso em: 15 ago. 2015.

TEIXEIRA, A. L. O. Linha da Pequena Empresa atende na Cidade Baixa. Prefeitura Municipal de Porto Alegre, Porto Alegre, ago. 2012. Disponível em $<$ http://www2.portoalegre.rs.gov.br/> Acesso em: 15 ago. 2015. 